Jurnal Konstruksi Hukum | ISSN: XXXX | E-ISSN: XXXX Vol. 1, No. 2, Oktober 2020, Hal. 416-420| Available Online at https://www.ejournal.warmadewa.ac.id/index.php/jukonhum DOI: https://doi.org/10.22225/jkh.1.2.2536.416-420

\title{
PERLINDUNGAN HUKUM KARYAWAN PT. ARTA SEDANA RETAILINDO YANG TERKENA PEMUTUSAN HUBUNGAN KERJA ATAS KLAIM BPJS KETENAGAKERJAAN
}

\author{
I Made Anggra, I PT GD Seputra, Luh Putu Suryani \\ Fakultas Hukum Univwersitas Warmadewa, Denpasar - Bali, Indonesia
}

\begin{abstract}
Abstrak
Hukum perlindungan tenaga kerja seharusnya memberikan rasa aman bagi tenaga kerja dalam bekerja, atau dengan kata lain, tenaga kerja tidak perlu was-was dalam bekerja. Salah satu yang menjadi permasalahan pekerja tentang hak-hak mereka yang terdapat di dalam BPJS Ketenagakerjaan ialah ketika ada pemutusan hubungan kerja (PHK) terjadi. Terkait dengan hal ini, penelitian mengkaji dua hal: bentuk perlindungan hukum bagi karyawan PT. ASR yang terkena PHK terkait dengan klaim BPJS Ketenagakerjaan dan penegakan hukum yang dapat ditempuh oleh karyawan PT. ASR yang terkena PHK terkait dengan klaim BPJS Ketenagakerjaan. Penelitian ini bertujuan untuk mengetahui bentuk perlindungan hukum dan upaya penegakan hukum yang ditempuh oleh karyawan yang terkena PHK atas klaim BPJS Ketenagakerjaan. Penelitian ini merupakan penelitian hukum empiris dengan pendekatan sosiologis. Penelitian dilakukan di PT. ASR dan data diperoleh dari wawancara dan kajian perundang-undangan. Hasil penelitian menunjukkan bahwa perlindungan hukum tenaga kerja PHK terdapat dalam kontrak kerja dan keikutsertaan tenaga kerja dalam BPJS Ketenagakerjaan mengacu pada Undang-undang No. 13 Tahun 2003 Pasal 156 ayat (1), (2), (3) dan (4), Undang-undang No. 24 Tahun 2011 BPJS Ketenagakerjaan dan upaya penegakan hukum yang dilakukan berbentuk preventif dan represif. Sektor perusahaan yang memperkerjakan tenaga kerja, dalam melakukan pemutusan hubungan kerja kepada karyawan, mesti benar-benar tidak mengesampingkan kewajiban-keawibannya yang menjadi hak-hak karyawannya.
\end{abstract}

Kata Kunci: BPJS Ketenagakerjaan; Pemutusan hubungan kerja; Perlindungan hukum

\begin{abstract}
Labor protection laws should provide a sense of security for workers at work, or in other words, workers may no more need to worry about working. One of the problems with workers regarding their rights contained in Social Security Administration Bodyfor Manpower (BPJS Ketenagakerjaan) is when a termination of employment (PHK) occurs. In this regard, the research examines two issues: the form of legal protection for employees of PT. ASR imposed PHK related to BPJS Ketenagakerjaan claims and law enforcement that could be taken by the laid-off employees in question. This study aims to examine the form of legal protection and law enforcement efforts taken by employees who have been laid off due to BPJS Ketenagakerjaan claims. This research is an empirical legal research with a sociological approach. The research was conducted at PT. ASR and data were obtained from interviews and statutory studies. The results showed the legal protection for laidoff workers is set forth in the work contract and the labor participation in the BPJS Ketenagakerjaan refers to Law No. 13 of 2003 Article 156 paragraphs (1), (2), (3) and (4), Law No. 24 of 2011 of BPJS Ketenagakerjaan and law enforcement efforts undertaken are in the form of preventive and repressive forms. The corporates employing workers, in terminating the employment of employees, should absolutely not override their obligations which are the rights of their employees.
\end{abstract}

Keywords: Termination of Employment; BPJS Ketenagakerjaan; Legal Protection

\section{PENDAHULUAN}

Perlindungan hukum dan kesejahteraan tenaga kerja di sektor perusahaan merupakan hal yang harus diperhatikan (Prajnaparamitha \& Ghoni, 2020), karena kesejahteraan dalam suatu perusahaan akan menjadi tolak ukur suskesnya pengusaha dalam menjalankan perusahaanya, namun dalam era ini masih banyak konflik yang terjadi antara pekerja dengan perusahaan dengan masalah hak dan kewajiban. Perusahaan yang mengalami kesulitan atau kendala dari sisi keuangan akan memilih untuk 
melakukan pemutusan hubungan kerja terhadap karyawannya (Mawey, Murni, \& Roring, 2016; Sunija, Febriani, Raharjo, \& Humaedi, 2020). PT. ASR merupakan perusahaan yang bergerak dibidang Retail dengan konsep modern yang memiliki cabang diseluruh Bali. Pada bulan Desember 2017 telah melakukan pemutusan hubungan kerja terhadap karyawannya yang dikarenakan kondisi keuangan perusahaan yang belum stabil sehingga beban biaya yang tidak seimbang dengan pendapatan. Dampak dari kondisi keuangan tersebut menyebabkan beberapa hal yang berkaitan pada hak tenaga kerja yang mengalami pemutusan hubungan kerja tersebut salah satunya adalah hak tenaga kerja dalam klaim BPJS Ketenagakerjaan (Mani, 2019). Hal tersebut terjadi dikarenakan perusahaan yang belum mampu memenuhi kewajibannya dalam membayar iuran, namun saat ini permasalahan tersebut sudah tertuntaskan dan tenaga kerja yang mengalami pemutusan hubungan kerja sudah terpenuhi haknya yaitu klaim BPJS Ketenagakerjaan atas upaya perusahaan yang sudah berkomitmen dalam penuntasan pembayaran iuran BPJS Ketenagakerjaan.

Berdasarkan latar belakang diatas, maka penelitian ini dirumuskan untuk untuk Mengetahui bentuk perlindungan hukum karyawan PT. ASR yang terkena pemutusan hubungan kerja atas klaim BPJS Ketenagakerjaan, dan untuk mengetahui upaya penegakan hukum yang dapat ditempuh oleh karyawan PT. ASR yang terkena pemutusan hubungan kerja terkait klaim BPJS Ketenagakerjaan.

\section{METODE PENELITIAN}

Tipe penelitian hukum yang digunakan dalam penelitian ini adalah tipe penelitian hukum empiris (Ali, 1998), Oleh karena itu, pembahasannya dilakukan dengan meneliti langsung di lapangan dan menganalisa dari aturan-aturan yang berlaku. Pendekatan yang digunakan adalah pendekatan yuridis sosiologis yaitu mengidentifikasi dan mengkonsepsikan hukum sebagai Isntitusi sosial yang real dan fungsional dalam sistem kehidupan yang nyata. Berdasarkan jenis penelitian yang digunakan yaitu penelitian hukum empiris yang menggunakan data Primer dan data sekunder, yang merupakan kajian dari dokumen-dokumen, maka penelitian dilaksanakan di PT. ASR, dalam rangka mengidentifikasi data-data secara sistematis.

1. Data primer yaitu hasil data diperoleh langsung dari lapangan yang dijadikan lokasi/ objek peneletian yaitu dari PT. ASR. Adapun data primer yang diperoleh dari informasi responden beracuan pada judul yang diambil mengenai pemutusan hubungan kerja dan klaim BPJS Ketenagakerjaan

2. Data sekunder, yaitu data yang diperoleh dari buku-buku serta peraturan undang-undang sebagai pelengkap data primer yaitu Perundang-undangan seperti Undang-undang No.40 Tahun 2004, Undang-undang No 13 Tahun 2003, Undang-undang No 24 Tahun 2011, Peraturan Perundangan Program Jamsostek dan beberapa buku.

Teknik pengumpulan data dengan melakukan wawancara langsung dengan bertatap muka dan mengajukan pertanyaan-pertanyaan berkaitan dengan penelitian, guna memperoleh informasi yang akurat dari responden. Data dianalisis secara deskriptif-kualitatif dengan cara menafsirkan dan mengkontruksikan pernyataan yang terdapat dalam dokumen dan perundang-undangan yang diperoleh dari hasil penelitian yang kemudian disusun dan dirangkum berdasarkan keseragamanya kemudian disusun serta dianalisis secara deskriptif sehingga memudahkan penalarannya.

\section{HASIL DAN PEMBAHASAN \\ Bentuk Perlindungan Hukum Karyawan PT. ASR yang Terkena Pemutusan Hubungan Kerja atas Klaim BPJS Ketenagakerjaan}

Pemutusan Hubungan Kerja (PHK) menurut pasal 1 angka 25 UU Nomor 13 Tahun 2003 tentang ketenagakerjaan adalah pengakhiran hubungan kerja karena suatu hal tertentu yang mengakibatkan berakahirnya hak dan kewajiban antara pekerja/buruh dengan pengusaha. Dalam PHK ini perusahaan wajib memperhatikan kesiapan perusahaan atas hak-hak yang harus diterima oleh tenaga kerja yang terkena PHK terdapat pada pasal 156 ayat 1-4 UU Nomor 13 Tahun 2003 tentang ketenagakerjaan. Jenis PHK yang dilakukan oleh PT. ASR adalah jenis PHK oleh perusahaan karena PHK terjadi atas kemauan perusahaan dengan alasan perusahaan yang kondisi keuangan yang tidak stabil. Hak-hak tenaga kerja yang terkena PHK antara lain uang penghargaan masa kerja, uang prestasi kerja dan uang pengganti hak selain itu hak tenaga kerja atas keikutsertaannya dalam program Badan Penyelenggara Jaminan Sosial (BPJS) ketenagakerjaan. 
BPJS Ketenagakerjaan dibentuk berdasarkan asas kemanusiaan, manfaat dan keadilan sosial bagi seluruh masyarakat Indonesia. BPJS dibentuk dengan tujuan mewujudkan terselenggarakannya pemberian jaminan terpenuhinya kebutuhan dasar hidup yang layak bagi peserta dan atau anggota keluarganya. Menurut UU Nomor.24 Tahun 2011 pada pasal 6 ayat (2) Badan Penyelenggara Jaminan Sosial Ketenagakerjaan menyelenggarakan beberapa program diantaranya Jaminan Kecelakaan Kerja, Jaminan Hari Tua, Jaminan Pensiun dan Jaminan Kematian. Aturan yang berlaku oleh perusahaan mengenai BPJS Ketenagakerjaan yaitu pendaftaran tenaga kerja sebagai peserta BPJS Ketenagakerjaan, prosedur pembayaran iuran yang secara perhitung an iuran dibebankan oleh tenaga kerja dan perusahaan serta iuran tersebut wajib disetorkan perusahaan ke BPJS Ketenagakerjaan setiap bulan. Jika terjadi pelanggaran atas pembayaran iuran maka perusahaan akan dikenakan sanksi dan denda dari besaran iuran tersebut. Jika tenaga kerja sudah berstatus tidak bekerja atau tenaga kerja mengalami PHK maka tenaga kerja bisa melakukan klaim BPJS Ketenagakerjaan sesuai dengan aturan yang berlaku pada PP Nomor 60 Tahun 2015.

Perlindungan hukum karyawan PT. ASR terhadap atas klaim BPJS Ketenagakerjaan yaitu Karyawan dapat melakukan tuntutan ke perusahaan atas hak nya dalam proses klaim BPJS Ketenagakerjaan, Perlindungan hukum tenaga kerja PHK terdapat pada pasal 156 ayat (1), (2), (3) dan (4) menyangkut tentang hak-hak tenaga kerja yang di PHK, Perlindungan hukum tenaga kerja yang ikut serta dalam program BPJS Ketenagakerjaan yaitu terdapat pada pasal 15 ayat (1) UU No.24 Tahun 2011, Perlindungan hukum tenaga kerja dalam proses klaim atau pencairan BPJS Ketenagakerjaan terdapat pada PP No.60 Tahun 2015 dan Perjanjian kerja/Kontrak kerja dari karyawan PT. ASR yang menjelaskan mengenai Jaminan Sosial.

\section{Upaya Penegakan Hukum yang Ditempuh oleh Karyawan PT. ASR yang Terkena PHK Terkait dengan Klaim BPJS Ketenagakerjaan}

Upaya penegakan hukum adalah usaha atau upaya untuk mewujudkan ide-ide dan konsep-konsep hukum yang diharapkan rakyat menjadi kenyataan dengan proses melibatkan banyak hal (Husni, 2009). Hal ini diberikan antara para pihak guna penyelesaian sengketa yang terjadi. Upaya penegakan hukum bertujuan agar terselesaikannya sengketa yang terjadi, sehingga mendapatkan titik terang antar para pihak. Upaya penegakan hukum bagi tenaga kerja yang terkena pemutusan hubungan kerja wajib dilakukan apabila perusahaan yang tidak memenuhi kewajiban atas hak-hak tenaga kerja yang mengalami pemutusan hubungan kerja tersebut. Adanya ketidaksesuaian hak antara tenaga kerja dengan perusahaan yang melakukan pemutusan hubungan kerja dapat diajukan atau dilakukan tuntutan atas perselisihan hubungan insutrial. Upaya penyelesaian perselisihan hubungan industrial dapat dilakukan dengan secara bipartite, mediasi, konsiliasi, dan arbitrase. Tenaga kerja PT. ASR yang terkena PHK yang mengalami kendala atas hak nya dalam klaim BPJS Ketenagakerjaan apabila tidak mendapatkan penyelesaian atau titik terang, maka tenaga kerja dapat melakukan tuntutan upaya penegakan hukum. Upaya penegakan hukum yang ditempuh oleh karyawan PT. ASR yang terkena PHK adalah: upaya penegakan hukum preventif dan upaya penegakan hukum represif.

Upaya penegakan hukum preventif adalah merupakan tindakan pemerintah didasarkan pada kebebasan bertindak, upaya hukum preventif bertujuan untuk mencegah terjadinya sengketa (Asyahdie, 2008). Upaya hukum preventif yang dilakukan oleh tenaga kerja guna mendapatkan suatu keputusan yang seadil-adiilnya oleh perusahaan kepada tenaga kerja yang mengalami pemutusan hubungan sehingga tidak terjadi konflik yang berkelanjutan dalam hal hak tenaga kerja. Upaya penegakan hukum preventif yang digunakan oleh karyawan PT. ASR yang terkena PHK dianggap lebih efektif karena penyelesaianya dilakukan dengan mediasi dan sosialisasi sehingga atas permasalahan tersebut mendapatkan titik terang yaitu karyawan PT. ASR yang terkena PHK dengan manajemen PT. ASR sudah menyepakati bahwa PT. ASR mengupayakan memenuhi kewajibanya dalam membayar iuran dan hasil akhir perusahaan PT. ASR sudah memenuhi komitmenya dan karyawan PT. ASR yang terkena PHK sudah mendapatkan haknya dalam klaim BPJS Ketenagakerjaannya sesuai dengan aturan yang berlaku pada BPJS Ketenagakerjaan.

Upaya Penegakan Hukum Represif adalah penegakan hukum yang dilakukan dengan cara menindaklanjuti pelanggar hukum (Asikin, 2014). Upaya penegakan hukum represif ini bertujuan agar pelanggar hukum mendapatkan keputusan tegas atas konflik yang terjadi. Seperti halnya suatu tindakan atas tuntutan yang dilakukan oleh pihak yang merasa dirugikan, jika tuntutan yang dilakukan tidak mendapatkan keputusan yang tepat dan tidak ditindaklanjuti sesuai dengan aturan yang berlaku 
maka pihak yang merasa dirugikan tersebut dapat melakukan tindakan berupa pengaduan ke tingkat yang lebih tinggi yaitu ke tingkat pengadilan sesuai dengan kasus yang terjadi. Upaya penegakan hukum represif dapat dilakukan oleh karyawan PT. ASR yang terkena PHK apabila dari perusahaan tidak memenuhi komitmen yang sudah disampaikan. Upaya penegakan hukum represif yang dilakukan oleh karyawan PT. ASR yang terkena PHK seperti: Pengaduan ke Dinas Tenaga Kerja Provinsi kemudian akan dilakukan mediasi antara karyawan yang di PHK dengan Manajemen PT. ASR, jika tidak membuahkan hasil, maka dilanjutkan dengan pengaduan hasil mediasi ke Dinas Hubungan Industrial kemudian akan diproses melalui Pengadilan Hubungan Industrial. Berdasarkan hasil penelitian, bahwa karyawan PT. ASR yang mengalami pemutusan hubungan kerja atas klaim BPJS Ketenagakerjaan tidak sampai ke pengadilan hubungan industrial, karena upaya penegakan hukum yang ditempuh atau dilakukan oleh karyawan adalah upaya penegakan hukum preventif, dan hasil dari tuntutan yang dilakukan oleh tenaga kerja PT. ASR yang mengalami pemutusan hubungan kerja sudah mendapatkan keputusan yang tegas dan tepat. Keputusan yang dimaksud adalah bahwa karyawan PT. ASR yang mngalami pemutusan hubungan kerja sudah mendapatkan haknya berupa klaim BPJS Ketenagakerjaan, sesuai dengan janji dari perusahaan atau manajemen PT. ASR telah melakukan pembayaran iuran secara bertahap atau dicicil. Dan konflik antara karyawan PT. ASR yang mengalami pemutusan hubungan kerja dengan perusahaan atas klaim BPJS Ketenagakerjaan sudah tertuntaskan dan tidak ada tuntutan lagi mengenai hal tersebut.

\section{SIMPULAN DAN SARAN \\ Simpulan}

Berdasarkan uraian di atas, dapta disimpulkan bahwa bentuk perlindungan hukum karyawan PT. ASR yang terkena Pemutusan Hubungan Kerja atas klaim BPJS Ketenagakerjaan yaitu terdapat pada kontrak kerja yang sudah disepakati, UU Nomor.13 Tahun 2003 tentang Ketenagakerjaan yang tertuang dalam pasal 156 ayat (1), (2), (3) dan (4) mengenai hak-hak tenaga kerja yang mengalami pemutusan hubungan kerja, UU Nomor.24 Tahun 2011 BPJS Ketenagakerjaan tertuang dalam pasal 15 ayat (1) dan PP Nomor 60 Tahun 2015 perlindungan hukum tenaga kerja dalam proses klaim atau pencairan BPJS Ketenagakerjaan. Kemudian, upaya penegakan hukum yang ditempuh oleh karyawan PT. ASR yang terkena pemutusan hubungan kerja atas klaim BPJS Ketenagakerjaan yaitu upaya penegakan preventif dan upaya penegakan hukum represif. Dan upaya penegakan hukum yang digunakan oleh karyawan PT. ASR yang terkena pemutusan hubungan kerja adalah upaya penegakan hukum preventif, karena penyelesaian permasalahan tersebut sudah dilakukan dengan negosiasi dan mediasi tanpa ada tuntutan ke Pengadilan Hubungan Industrial. Upaya penegakan hukum preventif merupakan tindakan mencegah terjadinya sengketa sedangkan upaya penegakan hukum represif yaitu upaya penegakan hukum yang dilakukan dengan cara menindaklanjuti pelanggar hukum yang melakukan pelanggaran atas sengketa sehingga dapat diputuskan oleh pihak pengadilan hubungan industrial.

\section{Saran}

Adapun beberapa saran yang hendak disampaikan, yakni: kepada seluruh sektor perusahaan yang memperkerjakan tenaga kerja, dalam tindakan pemutusan hubungan kerja diharapkan benar-benar mempersiapkan terhadap kewajiban selaku perusahaan kepada tenaga kerja karena setelah PHK karyawan tentu akan kehilangan pekerjaan dan berimbas pada kelangsungan hidupnya. Kemudian, bagi tenaga kerja, jika tenaga kerja mengalami pemutusan hubungan kerja, maka berhak atas hak-hak yang harus diterima untuk nantinya digunakan sebagai bekal selama tidak bekerja atau statusnya sebagai pengangguran, jika hak tenaga kerja tidak terpenuhi maka tenaga kerja dapat melakukan tuntutan sesuai dengan aturan yang berlaku. Terlebih, bagi Pemerintah atau Instansi terkait, agar benar-benar diperhatikan mengenai aturan yang berlaku serta perlindungan hukum bagi tenaga kerja yang mengalami pemutusan hubungan kerja atas hak-haknya.

\section{DAFTAR PUSTAKA}

Ali, A. (1998). Menjelajahi Kajian Empiris. Makassar: Kencana.

Asikin, Z. H. (2014). Dasar-Dasar Hukum Perburuhan. Jakarta: PT RajaGrafindo Persada.

Asyahdie, Z. (2008). Hukum Kerja. Jakarta: PT RajaGrafindo Persada.

Husni, L. (2009). Hukum Ketenagakerjaan Indonesia (Edisi Revi). Jakarta: PT RajaGrafindo Persada. 
Mani, N. (2019). Perlindungan Hukum bagi Pekerja di Perusahaan yang Tidak Membayar Iuran BPJS Ketenagakerjaan Nurfatimah Mani : Perlindungan Hukum bagi. Media Iuris, 2(3), 373-392.

Mawey, Z. A., Murni, S., \& Roring, F. (2016). Faktor-Faktor Yang Mempengaruhi Pemutusan Hubungan Kerja. Jurnal EMBA, 4(1), 261-271.

Prajnaparamitha, K., \& Ghoni, M. R. (2020). Perlindungan Status Kerja Dan Pengupahan Tenaga Kerja Dalam Situasi Pandemi COVID-19 Berdasarkan Perspektif Pembaharuan Hukum. Administrative Law and Governance Journal, 3(2), 314-328.

Sunija, D. A., Febriani, S., Raharjo, S. T., \& Humaedi, S. (2020). Pekerja Sosial Industri dalam Menangani Permasalahan PHK di Dunia Industri Indonesia. Prosiding Penelitian Dan Pengabdian Kepada Masyarakat, 6(3), 181-191. 